\title{
Promoting University English Majors' Learner Autonomy in the Chinese Context
}

\author{
Haiyan Wang \\ College of Foreign Languages, Qingdao University of Science and Technology, Qingdao 266061, China \\ Email: haiyanwang417@163.com
}

\begin{abstract}
According to a survey conducted among some local colleges and universities, the author found that the current English teaching in Chinese colleges and universities is mostly "teacher-centered". The "teacher-centered" teaching mode poses problems to students, especially to their learner autonomy. The students may see knowledge as something to be transmitted by the teacher rather than discovered by themselves. They, therefore, are less autonomous, more dependent on authority figure. It reduces the student from an autonomous learner, creative and critical thinker, as they should be, to a mechanical recipient of knowledge. Not only is this result at odds with our country's educational goal, but it will hamper students' improvement in the long run. There is saying that learner autonomy is not suitable to the Chinese context. This paper mainly discusses one question-Is it really true that learner autonomy is not suitable to the Chinese context and gives a negtive answer to this question from theoretical element and data analysis.
\end{abstract}

Index Terms - teacher-centered teaching mode, learner autonomy, Chinese context

\section{INTRODUCTION}

Language teaching has developed so quickly and the main stream is from teacher-centeredness to learner-centeredness. With the main stream, the concept of "learner autonomy" has been raised. In other words, there is growing interest in defining how learners themselves make conscious efforts in mastering a foreign language. In China, to help a language learner become autonomous one is one of the leading educational goals.

On the one hand, Chinese learners lack the ability of learner autonomy; on the other hand, there is saying that learner autonomy is not suitable to the Chinese context. This paper mainly researches this question: Is it really true that learner autonomy is unsuited to the Chinese context?

\section{CURRENT “TEACHER-CENTERED” Mode In CHINESE LANGUAGE ClasseS}

This chapter begins with a survey, according to which problems of current language teaching in China have been found. Analyzing causes of this teacher-centered teaching mode, the author raised the hypothesis of promoting learner autonomy in the Chinese cultural context.

\section{A. A Survey}

This survey was carried out among a hundred and fifty university English majors. Among the students investigated, sixty from Liao Ning Normal University, forty from Northeastern Finance and Economics University, thirty from Da Lian Maritime University and the rest from other local universities.

One same question was designed for these students: "What's the percentage of the teacher's prelection in class?"

Table 1 shows the result with the university students.

TABLE 1
\begin{tabular}{|l|l|l|l|}
\hline Items & Number of the students & Total number & Percentage \\
\hline $21-40 \%$ & 7 & 150 & $4.7 \%$ \\
\hline $41-60 \%$ & 32 & 150 & $21.3 \%$ \\
\hline $61-80 \%$ & 69 & 150 & $46 \%$ \\
\hline Over80\% & 42 & 150 & $28 \%$ \\
\hline
\end{tabular}

In this table, "Item" in the first column lists the percentage of teacher's prelection during a comprehensive period. "Number of the students" in the second column refers to the respective number of the students who chose the percentage in the same row. "Total number" in the third column is the total number of students investigated. "Percentage" in the fourth column lists the respective statistical percentage of the students who chose the corresponding prelection percentage.

It can be easily seen from the table that at present, English teaching in Chinese colleges and universities is mostly "teacher-centered". The students admit that although there are some language activities in class, the teacher's prelection takes the most of the time.

B. Problems of the Teacher-centered Teaching Mode 
This teacher-centered teaching style is often based on the assumption that the teacher is the "knower" and has the task of passing over this knowledge to the students. It is sometimes characterized as "jug and mug"- the knowledge being poured from one receptacle into another empty one. This is probably done mainly by teacher explanations with occasional questions to or from the learners. There seems to be an assumption that having something explained or demonstrated to you will lead to learning. After these explanations, the students will often do some practice exercises to test whether they have understood what they have been told. Throughout the lesson the teacher keeps controls of the subject matter, makes decisions about what work is needed and orchestrates what the students do. In this kind of classroom, the teacher probably does most of the talking and is by far the most active person. Gradually, both the teacher and students will get used to this teaching mode and the students, ultimately, tend to rely on the teacher solely. For example, in class, since the teacher explains either the grammar or the content of the text for most of the time, students get used to it and regard it as the teacher's responsibility to tell and explain everything. When the teacher occasionally asks questions, those need either profound thinking or very simple ones. Many students, instead of exerting their brains thinking, just sit and wait for the easy answers from the teacher or other students. Few students take the risks to express their own opinions and doubts. The process is rather mechanical, and the classroom atmosphere is dull and tense. On the whole, students' oral proficiency is rather weak and they lack motivation, or authority in learning.

So most students see knowledge as something to be transmitted by the teacher rather than discovered by the learners. They regard the teacher as the authority and are disturbed if this does not happen.

But the question is: If they have the teacher as their authority at school, what if the class is over? What if they graduate from the school?

Obviously, the learning of a foreign language is not completed upon graduation, but is a life-long process. If the learner has got used to the teacher-centered mode at school, where the teacher gives instructions and arranges everything for him, he may feel frustrated without the presence of a teacher, he may even feel confused at what and how he should learn, such a learner is unlikely to succeed in his future improvement.

Therefore, the teacher-centered method cannot serve as a satisfactory way to achieve the teaching goal. Rather than facilitate student's learning, it reduces the learner from an autonomous learner, a creative and critical thinker, who they are supposed to be, to a mechanical recipient of knowledge. Not only is this result at odds with our country's educational goal, but it will hamper students' improvement of language and take its toll on their learning process because of a want of autonomy. In view of the defects brought about by the teacher-centered method, a new method must be called upon to solve, at least ameliorate, the current problems of Chinese English teaching and promote learner autonomy.

\section{Hypothesis of Promoting Learner Autonomy in the Chinese Context}

Based on the above discussion, i.e. the negative aspects of China's English education, the importance of learner autonomy for language learners which we will discuss in detail in the following parts, the author presents the hypothesis of promoting university English majors' learner autonomy in the Chinese context, with the aim of helping them know how to "fish" for their whole lifetime. In that case, even if the class is over, if they graduate from school, the language learners in China will still do a good job all by themselves, i.e. from teacher dependence to autonomy. And also they are likely to succeed in their future improvement.

\section{The SignifiCANCE OF AutONOMY}

The importance of autonomy is sometimes explained in terms of a positive relation between present and future learning. Learners who accept responsibility for their learning are more likely to form a virtuous circle to achieve their learning targets. When they achieve their learning targets, they are more likely to maintain a positive attitude to learning in the future. If not properly trained in the capacity to learn for themselves, students have little incentive to undertake learning outside their studies (Lee, 1998). In school, Chinese students tend to demand more direct input from teachers as to what to be learned, what to be done. They show a strong belief in the importance of repetition, memorization and systematic error correction, which is a ubiquitous phenomenon in the Chinese educational system. This kind of passive learning attitude makes learners ill-adapted to the learning environment further up the education ladder or when they have to depend on themselves for individual pursuit of language use outside the classroom. So it has never been more significant to advocate autonomy at the college level. Both teachers and students should be aware of the goal of language education, that is, to develop student autonomy in learning. Language learning, as Thomson (1996) puts it, is "a lifelong endeavor". But, for anyone to be capable of learning life-long, he/she has to be an autonomous learner first, which means that he/she should develop the capacity to learn independently if there is not a teacher around. That's why it is important for students to become aware of its value, to acquire the habit of learning continuously, and maintain it after they have completed their formal studies.

\section{A. Social Demand}

We foster and promote the goal of language education--learner autonomy because of two demands--social and personal--set on learners when they step into society. On the one hand, it is specified in the College English Teaching Syllabus (1999) that students should become autonomous learners with the help of teachers to cultivate language sense, 
to acquire good language learning methods and to improve their self-learning abilities. On the other hand, it is the requirement of the world we live in today, which needs new knowledge constantly rather than the ability to repeat old knowledge. In a time when the world is undergoing amazingly fast changes in the field of culture, economy, science and technology, new things keep coming up. If one does not keep abreast with the development of society by continuing learning upon completion of his/her formal education, he/she will surely be left behind. In this world of changes, the successful learner is increasingly seen as a person who is able to construct knowledge directly from experience of the world, rather than one who responds well to class instruction. Thus there are needs for people to learn skills to deal with the globalization and mobility of economic and political life with evident implications for language learning. In addition, with our country's opening policy to the outside world, and its entry into the WTO, people have an ever-growing demand to learn about foreign languages and cultures either in their daily life or in their work. Rogers (1983) states the needs boldly: "The only man who is educated is the man who has learned how to learn; the man who has learned how to adapt and change; the man who has realized that no knowledge is secure, that only the process of seeking knowledge gives a basis for security." And it is because of these demands in society that a learner must develop the capacity.

\section{B. Personal Demand}

Besides social demands, there is the demand for personal and career development. Independent learning at university is preparation for learning after university. Since a one-time "dose" of study skills in educational institutions will not serve the learner for life, he/she needs to experience new things and learn constantly to perfect himself/herself, for example, further education abroad, job promotion, migration and tourism, etc. It is thus necessary for people to have a parallel development in specialist skills together with new patterns of work and life. So if the learner has the growing awareness of learning by himself or herself when the teacher is not around, he/she will be better qualified on the job or as a social being. For example, if someone ventures to invest in shares, he/she will need to find out what he/she needs to learn first (needs analysis), plans what to learn (planning), studies the stock market and the causes of rises and falls in share prices (studying), then practices by buying and selling shares, then reviews his/her performances and the profit or loss (monitoring), and finally decides what to learn next to improve his/her performance (further planning). This is exactly what an autonomous learner does as he/she is learning in school. He/she can transfer this ability to study to learning new things. Those empowered with this capacity to take charge of his/her own learning will turn out to be a well-organized, self-managing learner and a highly efficient person. Therefore, whatever work they will do in future, they are likely to succeed in their lifelong learning process and bound to refine themselves in the overall quality required both internally and externally.

\section{Promoting Learner Autonomy in the Chinese Cultural ConteXT}

\section{A. Theoretical Element}

Learner autonomy is not restricted to the Western context and is also suitable to the Chinese cultural context because of its internationality. The following parts back this point from the aspect of theory.

1. Autonomy: in Search of a Culture-free Definition

As what the paper discussed above, many researchers have defined learner autonomy in different aspects. The concept of autonomy has associations with independence, self-fulfillment, freedom from external constraints and authoring one's own world without being subject to the will of others. It is primarily these associations which have caused many writers to suggest that autonomy may have little relevance outside the "individualistic" Western contexts in which it first rose to prominence.

Actually, if people define autonomy in educational terms as involving students "capacity to use their learning independently of teachers, this is a culture-free definition for autonomy. And from it, autonomy would appear to be an incontrovertible goal for learners everywhere, since it is obvious that no students, anywhere, will have their teachers to accompany them throughout life. If people take autonomy to include not only autonomy as a communicator but also autonomy as a learner, it seems uncontroversial to say that the demands of a changing world will impose on learners of all cultures the need to learn without the help of teachers. Indeed, the need for students to develop greater capacity to think independently and ask questions rather than conform is one of the most frequent messages heard in keynote papers at conferences in East Asia (e.g. Gandart 1997 in Malaysia; Kirtikara 1996 in Thailand). And as one part of East Asia, China is of course beyond the exception.

2. The Nature of Learners

From the part of the desirability of learner autonomy, learners are intelligent, fully functioning humans, not simply receptacles for passed-on knowledge. So learning is not simply a one-dimensional intellectual activity, but involves the whole person. There is a key phrase here - the whole person.

Recent approaches in EFL have increasingly acknowledged the importance of the "whole person" in the learner (as opposed to only their mental processes such as thinking, remembering, analyzing, etc). Teachers can no longer be content with the image of the student as a blank slate. Students may bring pen and paper to the lesson. But they also bring a whole range of others, less visible things to the class: their needs, their wishes, their life experience, their home background, their memories, their worries, their day so far, their dreams, their anger, their toothache, their fears, their moods, etc. Given the opportunities, they will be able to make important decisions for themselves, to take responsibility 
for their learning and to move forward. So does it seem different that learners in all learning cultural contexts (western concept as well as eastern concept) share the same characteristic as a "whole person"? So from this point, autonomy in language learning is also suited to the Chinese context.

3. Conclusion

There appears to be little evidence that autonomy is "more appropriate" in some cultures or "unsuitable" for other cultures. Rather, the requirement to take into account the specific backgrounds of teachers and learners is common to all teaching-learning settings. Although the eastern and western learners come from different ideological and pedagogical backgrounds, underlying both sets of value systems are strong similarities. These are the importance of creating self-esteem and self-reliance, cooperation, freedom of choice and mutual respect of the individual.

\section{B. Research Design of Applicability of Learner Autonomy in the Chinese Cultural Context}

People may acquire a clearer idea about the question that whether Chinese students are passive learners, unwilling to manage their own learning and believing in rote way of language learning only in Chinese learning culture by a rough study.

\section{Subjects}

The same subjects are selected randomly among university English majors from Liao Ning Normal University, Northeast Finance and Economics University, Da Lian Maritime University and other local universities. Among them, 25 had passed Graded Test for English Majors-8 (TEM-8), 54 had passed TEM-4. Among the rest who hadn't yet passed TEM-4, 39 had passed College English Test-6 (CET-6) and 32 had passed CET-4.

2. Instruments

The instrument used in the study was one questionnaire. The English Learner Belief Questionnaire consists of two parts (Appendix I provides a description of the Learner Belief Questionnaire). Part A concerns personal details (including name, sex, grade, date of birth and personal English proficiency). Part B consists of statements of beliefs about language learning. The students indicated their opinions in terms of a five-point scale from (1) "strongly disagree" to (5) "strongly agree".

In the process of designing the items in the questionnaire, Chinese cultural factors were taken into fully consideration. Two questionnaires were taken as reference. There are Wen Qiufang's The Learner Strategy Questionnaire (1995) and Littlewood's East Asian Students'Autonomy Questionnaire (1999).

3. Data Collection and Data Analysis

The author let classmates from different universities in Da Lian make subjects answer the English Learner Belief Questionnaire. The response rate was 100 percent. There are altogether 6 variables listed in Table 2, all with multiple indicators. The alpha value indicates the internal consistency within the multiple items.

4. Discussion of Findings (Chinese students' English Learning Beliefs)

TABLE 2

The AlPha Value of Students' Learning BelieF

\begin{tabular}{|l|l|}
\hline Variable Names & Alpha Value \\
\hline Management Belief & 0.58 \\
\hline Cooperative Belief & 0.42 \\
\hline Form-focused Belief & 0.49 \\
\hline Meaning-focused Belief & 0.69 \\
\hline Vocabulary Belief & 0.55 \\
\hline Tolerating-ambiguity Belief & 0.53 \\
\hline
\end{tabular}

\section{Conclusion}

By investigating Chinese university English majors' English learning belief, two basic facts about Chinese students learning behaviors related to Chinese learning culture have been demonstrated. The first is that Chinese students do not wish to be passive language learners. Instead, they strongly desire to take charge of their own language learning. They have firm beliefs in managing their own learning. So there is a need for us to reconcile ideas about the influence of Chinese culture with the recognition individual differences of Chinese students, as what have discussed in theoretical sheet. Although Chinese students are brought up under Chinese culture, which does not mean that they have been passively moulded by it or that all individuals will conform to the common pattern. The second is that Chinese traditional ways of language learning are as important as, if not more important than, untraditional ones in the Chinese context where there is no English-speaking community. The findings have significant implications to English teaching in the Chinese context.

\section{CONCLUSION}

This paper mainly concerns about promoting learner autonomy in the Chinese cultural context. Analyzing theoretical element and collection of data, this paper proves that learner autonomy is also suitable to the Chinese cultural context.

The author presents the hypothesis of promoting university English majors' learner autonomy in the Chinese context, with the aim of helping them know how to "fish" for their whole lifetime. 


\section{APPENDIX THE ENGLISH LEARNER BELIEF QUESTIONNAIRE}

Part A: Personal Details

Name: __ Sex:__ Grade:__ Date of birth:_

Your present English proficiency: _Below CET-4___CET-4 _ _ _ CET-6 _TEM-4

Part B: Beliefs about language learning

Below are beliefs that some people have about learning a foreign language. Read each statement and then decide if you:

$1=$ strongly disagree

$2=$ disagree

$3=$ neither agree nor disagree

$4=$ agree

$5=$ strongly agree

There are no right or wrong answers. We are simply interested in your opinions. Please according to the meaning represented by each number, choose and write down one number in the bracket at the end of each sentence.

Remember: the number you choose must represent your true opinions.

1. English knowledge is something to be "transmitted" by the teacher rather than "discovered" by the learner. ( )

2. Teachers, rather than learners themselves, are responsible for evaluating how well learner learn English. ( )

3. Students can learn English well simply by following teachers' instructions. ( )

4. It's important for students to set short-term and long-term goals in order to learn English well. ( )

5. It's important for students to evaluate their progress and find out their problems in learning English in order to learn it well. ( )

6. It's important to study in groups in order to learn English well. ( )

7. Students can learn English better by studying alone than by working with others. ( )

8. Individual learners should pay attention to the whole group's opinions and attitude when forming their own ones. ( )

9. It's important to support group goals and expectations. ( )

10. Memorizing sentence patterns is important for English study. ( )

\section{REFERENCES}

[1] Gaudart, H. (1997). "Meeting the challenge of quality and excellence in the English language classroom." Plenary paper presented at the $4^{\text {th }}$ MELTA Biennial Conference, Kuala Lumpur.

[2] Kirtikara, K. (1996). “Autonomy rediscovered." Plenty of paper presented at the Conference Autonomy 2000, KMIT, Bangkok.

[3] Lee, I. (1998). Supposing greater autonomy in language learning. ELT Journal, 52 (4).

[4] Littlewood, W. (1999). Defining and developing autonomy in East Asian Contexts. Applied_Linguistics,20 (1).

[5] Thomson, C. K. (1996). Self -assessment in self-directed learning: Issues of learner diversity. In Pemberton et al (Eds.) Talking control: Autonomy in language learning. Hong Kong: Hong Kong University Press.

[6] Pennycook, A. (1997). Cultural alternatives and autonomy. In P. Benson \& P. Voller (Eds.), Autonomy and independence in language learning. London: Longman. pp. 35-53.

[7] Rogers, C. (1983). Freedom to learn. Columbus: Merrill.

Haiyan Wang was born in Tai'an, China in 1979. She received her M.A. degree in linguistics from LiaoNing Normal University, China in 2005.

She is currently a lecturer in the School of Foreign Languages, Qingdao University of Science and Technology, Qingdao, China. Her research interests include linguistics and Language Teaching. 